\title{
Work-Life Balance versus Work-Life Merge: a Comparative and Thematic Analysis of Workplace Well-Being
}

\author{
Jennifer Sharkey \\ Undergraduate \\ Department of Psychology, Dublin Business School \\ Dublin, Ireland \\ Dr. Barbara Caska \\ Selection by Design \\ Dublin, Ireland.
}

(C) Jennifer Sharkey and Barbara Caskey. This work is licensed under the Creative Commons Attribution-NonCommercial-ShareAlike 4.0 International License. To view a copy of this license, visit https://creativecommons.org/licenses/by-nc-sa/4.0/ .

\section{Abstract}

The aim of this mixed-methods research study was to test the traditional concept of work-life balance, which suggests workers can experience better well-being by being able to psychologically switch on and off. Participants were 133 full-time workers, split into two groups according to where their job was performed strictly at their place of business, or from a combination of workplace and home. Each participant completed quantitative online surveys that measured their perceived stress, life satisfaction and job satisfaction. Results indicated participants who worked from a combination of the workplace and home had significantly greater job and life satisfaction levels than their workplace-based counterparts. However, no significant difference was found between the two groups on perceived stress. Participants also answered qualitative questions about how their job impacted their personal life, how their job might be changed to improve personal time, and what motivated them to work. A strong emergent theme centred around time. Many complained of long working hours, giving them very little time to spend with family, friends or on personal pursuits. For some, stress and worry about their jobs bled into their home life, culminating in moodiness and difficulty in psychologically switching off. Whilst others were happy with the balance between their working and private lives, many wished for fewer and more flexible working hours. Conclusions drawn suggest there is real merit in offering flexible constructs to today's workers in order to harvest better psychological well-being in the workplace.

Keywords: Work-life Balance; Work-life Merge; Job Satisfaction; Life Satisfaction; Perceived Stress.

\section{Introduction}

Work-life balance (WLB) is characterised by achieving a state of balance, where the demands of a person's occupation and personal life are equivalent. Time and energy are evenly split between work and home life (Gyanchandani, 2017). The concept of WLB has been a focus of organisational psychologists since the 1990s (Cooper and 
Cartwright, 1994), but it was not until the turn of the millennium that research into this area started in earnest (Chang, McDonald and Burton, 2010; Gambles, Lewis and Rapoport, 2006; Hughes and Bozionelos, 2007; Warren, 2015). Researchers have suggested that workers can successfully achieve WLB once they have clearly defined hours of work, effectively allowing them to psychologically switch on and off (Messersmith, 2007; Warhurst, Eikhof and Haunschild, 2008).

However, the validity of the traditional WLB viewpoint has been called into question (Warhurst, Eikhof and Haunschild, 2008), evidenced with findings of almost $70 \%$ of US workers reporting they are struggling to balance work and personal obligations (Schieman, Glavin and Milkie, 2009). Even the use of the term balance has been subjected to criticism (Day, Kelloway and Hurrell, 2014) by those who see it as misleading and not representative or relevant for today's Information Age workers (Day, Kelloway and Hurrell, 2014). The Information Age has changed the landscape of the organisation considerably with work driven by technology rather than physical labour. This has resulted in a change of lifestyle for employees and an increasing desire to work outside of the office (Attaran, Attaran and Kirkland, 2019). It may be useful to consider the implications of blending work with non-work hours as work-life merge (WLM) (Hinsliff, 2013). In the present study, WLM was examined to capture the lack of boundary between personal and working time that characterises employment arrangements for some individuals today.

Those working under conditions of WLB and WLM were compared across the wellbeing indicators of perceived stress, job satisfaction, and life satisfaction. To gain a greater understanding of the needs of today's workers, responses to three qualitative questions were also examined. These covered the impact and influence of work on one's personal life, and sources of work motivation.

\section{Rationale for Research}

Despite the concept of WLB being debated for decades, very few feasibility studies have been carried out on identifying psychologically healthy work environments and the impact, whether positive or negative, on employee well-being (Day, Kelloway and Hurrell, 2014). A meta-analysis by Chang, McDonald and Burton (2010) of 245 empirical WLB peer-reviewed research studies yielded inconsistent results. The researchers concluded that improvements in sampling frames and surveys/measures used were needed to identify and better understand how workplaces might impact the psychological well-being of their workers. Kelloway and Day (2005a) posited and stressed the importance of adopting a broad approach when analysing well-being in the workplace, embodying physical, psychological and societal contributing factors. Their holistic model looked at consequences in terms of individual outcomes, including physical, psychological and behavioural, organisational outcomes covering both employee and financial turnover, and societal outcomes such as government initiatives (Kelloway and Day, 2005b).

The shortcomings in previous studies are the key driving force behind the present research, which will strive to evaluate, analyse and understand the psychological wellbeing levels of today's Information Age workers. By drawing on Kelloway and Day's (2005b) holistic approach of encompassing outcomes pertaining to individuals, 
organisations and societal factors, it is hoped these findings will give employers greater insight into the needs of their workforce, and help them create psychologically healthier workplaces. Further, it was envisaged that the richness of data obtained through responses to the qualitative questions included in this study would offer unique insight into the perceived needs of today's employees.

\section{Literature Review}

\section{Work-life merge}

As an alternative to WLB, WLM has gathered traction with the emergence of the Information Age. Employees may not have the luxury of psychologically switching off once their workday is complete. This is especially true for those who work flexible hours (Chen and Karahanna, 2018). Such employees may have instant fingertip access to servers, email accounts and clients through portable devices, meaning jobs may be performed outside of the traditional workplace environment. However, this flexible work model can result in the lines that once very precisely separated work and personal lives being eroded. IT workers, for example, can reboot servers from home at night and take time off in lieu. They may also choose to work remotely during peak commuting times and use the time the next day to run a personal errand or visit a doctor. While this concept of WLM is relatively new, the seeds were first sown as far back as the 1990s, when an increasing number of organisations began to offer flexitime to employees (Kossek and Ozeki, 1999). However, Kossek and Ozeki (1999) found employees were slow to take up such opportunities due to existing company cultures, coupled with ignorance around its effectiveness both from an employee and employer perspective. Three decades later, the introduction of remote wireless technology has made the workplace virtually unrecognisable. Such technology has brought with it a surge of interest by jobseekers looking to work remotely, as evidenced in 2017 by one online Irish jobs search engine (Gordon, 2018).

This new way of working introduces a departure from the traditional WLB way of living, and presents new challenges for researchers interested in analysing well-being. For example, what are the consequences, if any, for workers who are permanently switched on psychologically?

\section{Job and life satisfaction}

The link between a satisfied workforce and greater productivity has received longstanding attention by theorists and researchers (e.g., Chmiel, Fraccaroli and Sverke, 2017). In the 1950s, psychologist Frederick Herzberg posited that making a job more interesting rather than simply increasing pay led to greater job satisfaction, as well as harvesting employee psychological growth (Herzberg, 1987). His two-factor motivation-hygiene theory suggested that motivation was the key to improved job satisfaction. Poor hygiene factors such as salary and environmental conditions lead to job dissatisfaction. Herzberg was quick to add that dissatisfaction is not the opposite of satisfaction, i.e., an improvement in hygienic factors is not sufficient to create satisfaction (1987). Hackman and Oldham (1975) constructed their job characteristics model consisting of five core dimensions: skill variety, task identity, task significance, autonomy and feedback. They suggested these factors influenced three critical psychological states relating to meaningfulness, responsibility and results. When 
these states were realised, increased motivation, performance and satisfaction would result, with decreased turnover and absenteeism (Hackman and Oldham, 1975).

More recently, Judge et al. (2001) conducted a meta-analysis of the relationship between satisfaction and performance. Their analysis of 312 correlations revealed a significant, yet moderate, corrected association of .30. The authors concluded that further evaluation of the mechanisms of the satisfaction-performance relationship was warranted. Zelenski, Murphy and Jenkins (2008) found a strong and consistent link between positive affect and productivity. Participants in their study were 75 middle managers employed in either the public or private sector. Links between affect and productivity were found at trait and state levels respectively: happy people were more productive, and people were more productive when happier.

Oswald, Proto and Sgroi (2015) determined that there are many advantages to achieving healthy levels of psychological well-being among employees. These included increased productivity and revenue, a more satisfied workforce, and ultimately, happier shareholders (Oswald, Proto and Sgroi, 2015). Greater well-being at work may bring about an improvement in employee creativity, productivity and loyalty, resulting in enhanced customer care (Sgroi, 2015). Such renewed positivity amongst the workforce may also benefit society at large, as well-being plays a key role in creating strong and thriving communities (Jeffrey et al., 2014).

In the present study, the job satisfaction measure used was affective rather than cognitive. Affective job satisfaction centres on workers' overall positive emotional judgment of their job (Moorman, 1993). It focuses on emotions by asking respondents about moods and feelings experienced when working. Positive feelings and positive mood are indicative of high job satisfaction. The first hypothesis of the present study was that there would be a significant difference between work-life balance (WLB) workers and work-life merge (WLM) workers on levels of affective job satisfaction (AJS).

\section{Stress and flexibility in the workplace}

Workplace stress is bad for business, with annual costs to employers in the region of $\$ 300$ billion in the US (Smith, 2016) and £5 billion in the UK (Russell et al., 2018). Recognising that employees are a company's most valuable resource is a must in today's fast paced and competitive working environment (Hyacinth, 2017). If companies place increasing shareholder value above workforce well-being, they may find themselves severely out of pocket or even bankrupt due to costs of fighting cases brought by disgruntled employees (Hyacinth, 2017).

Legislation in Ireland and the EU outlines a 'Duty of Care' employers have to their employees to ensure they are not unduly compromised at work (Health and Safety Authority, 2018). The Economic Social and Research Institute recently identified several key work stressors amongst workers in the UK and Ireland, including emotional demands, time pressure, bullying/harassment/violence, physically demanding work, effort-reward imbalance, and long working hours (Russell et al., 2018). The effects of such stressors may be reduced through creating support structures, developed through partnership between managers and co-workers 
(Russell et al., 2018). For example, Kelly et al. (2014) found that introducing increased supervisory support, with greater work schedule flexibility, resulted in decreased workfamily conflict, employees feeling more in control of their lives, and an increase in life satisfaction. Participants also reported receiving adequate time to spend with loved ones, delivering much-needed psychological boosts (Kelly et al., 2014).

Positive outcomes may be realised when employees are offered properly controlled flexible work options. This was demonstrated by Barnes (Ainge Roy, 2018). In an effort to improve employee well-being, the researcher ran a trial four-day working week, but still paid employees for five days. The result was increased job satisfaction and reduced stress. At the same time, the company suffered no loss of revenue or quality of service to its clients. As part of their extra four days off per month, each employee was obliged to work voluntarily in their local community one day per month (Ainge Roy, 2018). Volunteer work such as this not only serves the community, but also gives the employee an opportunity to give something back. Increases in both psychological wellbeing and self-reported health have been found among volunteers, particularly those who had a lower level of social integration than their counterparts (Piliavin and Siegl, 2007).

However, when not controlled properly, flexible offerings by employers can negatively impact employees and company performance. Research carried out at a large UK supermarket uncovered abuse in the management of zero-hours contracts implemented in order to keep costs down (Wood, 2016). Zero-hours contracts require employees to be available a certain number of hours per week, without specifying when. Wood (2016) found that the people working under zero-hour contracts experienced stress, negative effects on their personal lives, and poor feelings towards their employer. The Irish government recently outlawed the use of zero-hours contracts except in cases of emergency (Employment (Miscellaneous Provisions) Act 2018; Department of Employment Affairs and Social Protection, 2019), resulting in enhanced rights for workers. Employers can also benefit from such legislation. Researchers Motro, Ordonez and Pittarello (2014) found that zero-hours contracts can lead to lost revenue associated with dissatisfied customers, employee sick leave and legal challenges. Research from both self- and peer-reported studies of life satisfaction and subjective well-being strongly suggests that subjective well-being is a far-reaching and lasting phenomenon, not just a spur of the moment judgement (Pavot et al., 1991). In the present study, the second hypothesis was that there would be a significant difference in levels of well-being measured as a) perceived stress (PS) and b) satisfaction with life (SWL) between WLB and WLM workers.

Wood and Michaelides (2016) discovered that not all workers who wish for more autonomy and flexibility by being their own boss could escape the hazards of workrelated stress. They found that as demands on freelancers increased, so did their anxiety and stress levels. The researchers determined that an increase in working hours alone was not detrimental to well-being, but rather brought calmness and greater enthusiasm. If workload difficulty was increased, however, home life was negatively impacted. Interestingly, less time spent at home was associated with less work-family/non-work interference (Wood and Michaelides, 2016). This demonstrates that longer hours alone may not be an issue for employees, but if demands are 
unreasonable and workloads increase, stress can result. The third hypothesis of the present investigation was that there would be a significant difference in levels of satisfaction between WLM workers who have flexible working arrangements (WLM Flexi) and those who do not (WLM Non-flexi). Satisfaction was measured as both SWL and AJS.

Qualitative research has proven useful in providing perspective on work and non-work roles. Gyanchandani's (2017) qualitative study on work life balance reinforced the importance of uncovering and understanding employees' needs relative to their work, life, self and other issues, when implementing effective work-life policies. Murthy and Shastri (2015) found that gaining a greater understanding of coping strategies that workers employ to balance their work and home life may help organisations in designing employee-focused policies. In the present study, open-ended questions were used to examine participant perceptions of work motives, and the relationship between personal and working lives

\section{Methodology}

\section{Participants}

A convenience sample of 133 individuals voluntarily took part in this investigation. All gave informed consent for participation. Fifty respondents were male and 83 female. They ranged in age from 18-65 years. All were presently employed and worked a minimum of 20 hours per week.

Based on responses to questions on place of work, participants were assigned to either a WLB or WLM group. WLB $(n=90)$ employees worked solely from their place of business. WLM ( $n=43)$ persons worked partially from their organisation and from their home. According to reported availability of in-place flexible work arrangements with their employer, WLM participants were further classified as either WLM Flexi $(n=$ 31) or WLM Non-flexi $(n=12)$.

\section{Materials}

Questionnaires included items measuring the demographic variables of gender, age group, average hours worked per week, and place of work. Incorporated predeveloped measures included the Perceived Stress Scale (Cohen, Kamarck and Mermelstein, 1983), the Satisfaction with Life Scale (Diener et al, 1985), and the Brief Index of Affective Job Satisfaction (Thompson and Phua, 2012). Three qualitative questions developed for the present study were also included: How does your job impact or affect your personal life? What would you change about your job to enhance your personal life? What motivates you most about working?

The Perceived Stress Scale (PSS) is a self-report instrument designed to measure an individual's perception of stress during the past month (Cohen, Kamarck and Mermelstein, 1993). For the present study, a shorter 4-item version of the Perceived Stress Scale was used (PSS-4). This has been found to be a sufficient and suitable tool for assessing perceived stress levels (Vallejo et al., 2018). Sample items include: "In the last month, how often have you felt that you were unable to control the important things in your life?" and "In the last month, how often have you felt confident about your ability to handle your personal problems?" Items are rated on a 5-point Likert type 
scale ranging from never (0) to very often (4). Scores are totalled for a possible range of $0-16$. Higher scores indicate greater perceived stress. In the present study, internal reliability (Cronbach's $\alpha$ ) for this scale was .75 .

The Satisfaction with Life Scale (SWLS) measures the judgemental component of subjective well-being. Diener et al. (1985) reported a moderate to high correlation between SWLS and other scales measuring subjective well-being, providing evidence of construct validity. The SWLS consists of five items. An example is: "So far, I have gotten the important things I want in life." Each is rated on a 7-point Likert type scale, ranging from strongly disagree (1) to strongly agree (7). Scores are totalled, and range from a low of 5-9 to a high of 31-35. During the present investigation, internal reliability (Cronbach's $\alpha$ ) for this scale was calculated at .90

The Brief Index of Affective Job Satisfaction (BIAJS) was designed in response to criticism of previously developed measures of affective job satisfaction. Other scales were lengthy, and measured job satisfaction cognitively rather than affectively (Thompson and Phua, 2012). The BIAJS consists of four items and three distractor questions. Each is rated on a 5-point Likert type scale ranging from strongly agree (1) to strongly disagree (5). A sample item is "I find real enjoyment in my job." Total job satisfaction is indicated through summed responses, ranging from a low of 4 to a high of 20 . Higher scores are indicative of greater job satisfaction. In the present study, internal reliability was indicated with a Cronbach's a coefficient of .88 .

\section{Design and Analysis}

A prospective, mixed-methods research design was used. Between-subjects analysis provided comparison of self-reported levels of perceived stress, satisfaction with life, and affective job satisfaction across participant groups. A qualitative thematic examination was carried out on responses to the three open-ended questions examining the relationship between work and personal life, and determinants of work motivation. Braun and Clarke's (2006) six-steps of thematic analysis was used. The process began with familiarisation with data, followed by the creation of initial codes and identification of themes and sub-themes. Thematic maps were constructed, and acted as visual guides as themes and sub-themes were repeatedly reviewed and refined. Finally, a thematic report was then created, supported by direct quotes from participants.

\section{Procedure}

Participants were recruited through an online link which was posted on Facebook, Linkedln and WhatsApp. An information sheet advised participants of the nature of the study, and that it would take approximately 5-10 minutes to complete. As a prerequisite to participation, respondents were asked to indicate whether they were 18 years of age or older, worked a minimum of 20 hours per week, and consented to take part in this survey. Online surveys, created through Google Forms, were then completed anonymously. 


\section{Results}

SPSS v.25 was used to run descriptive and inferential statistical analysis. NVivo v.12 was used to carry out the thematic analysis of responses to the three qualitative questions.

\section{Descriptive statistics}

Of the 133 participants, 50 were male and 83 female. They ranged in age from 18-65. The largest proportion belonged to the $46-55$ age group (36.1\%), and the second most frequently indicated was the category of $26-35(26.3 \%)$.

Sixty-eight percent of the sample reported working solely from their place of employment (WLM); Thirty-two percent performed their jobs from a combination of their organisation and home (WLB).

Participants indicated the number of hours they worked on average per week. These are presented for the WLB group in Figure 1. For this group, hours ranged from 20-29 per week (16\%) up to 50-59 (9\%). Most persons (76\%) reported working in the overall range of 30-39 or 40-49 hours. A different pattern emerges for participants in the WLM group, as shown in Figure 2. Here, respondents indicated a wider variety of hours worked per week, with a close 3-way split between the categories of 20-29, 30-39 and 40-49. A slightly higher percentage of the WLM merge group worked over 50 hours per week (11\%), compared to WLB participants (9\%). The WLM group, alone, indicated a small percentage of persons working over 60 hours per week.

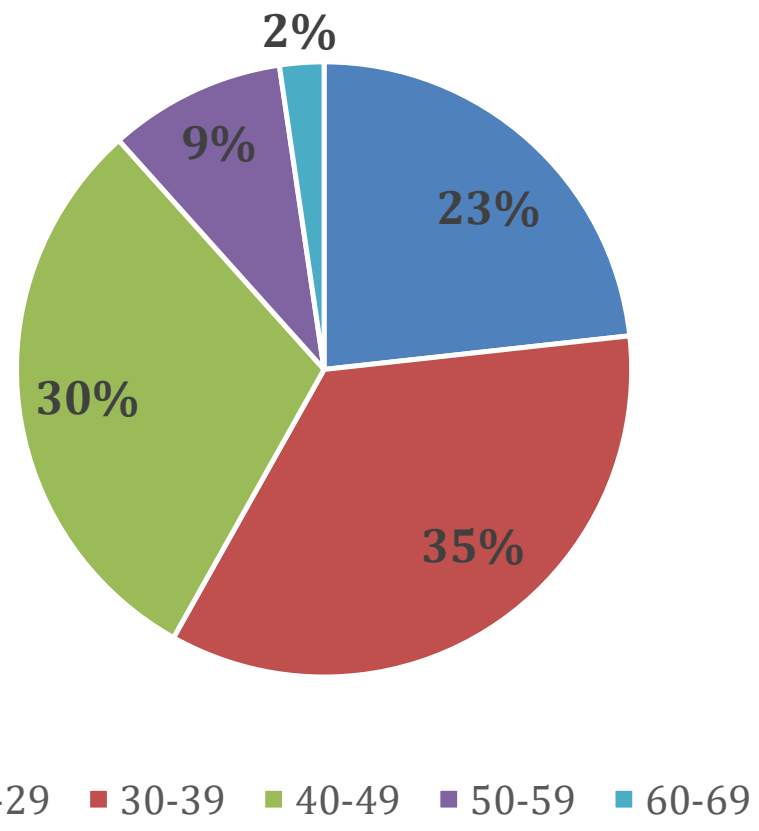

Figure 1: Average hours worked per week by the work-life balance group. 


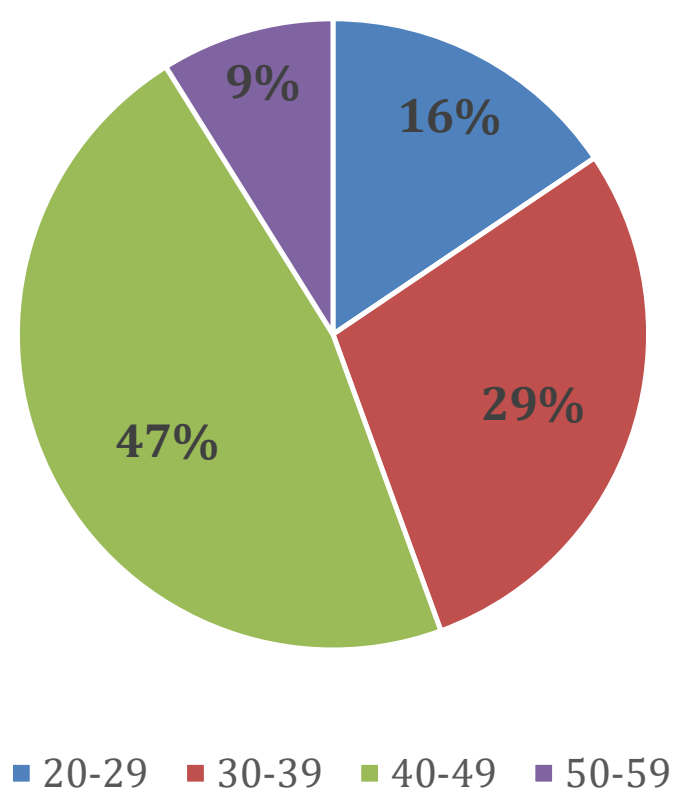

Figure 2: Average hours worked per week by the work-life merge group

Descriptive statistics for each of the scales completed by participants are presented in Table 1. Cronbach's alpha levels indicated acceptable internal consistency for each measure.

Table 1: Descriptive Statistics for Scales

\begin{tabular}{lllll}
\hline Scale & $\mathrm{N}$ & Mean & SD & Cronbach's $\alpha$ \\
\hline PSS & 127 & 6.20 & 2.76 & .75 \\
SWLS & 132 & 24.43 & 6.36 & .90 \\
BIAJS & 132 & 14.60 & 3.04 & .88 \\
\hline
\end{tabular}

Preliminary analysis of the data indicated violations of parametric assumptions. Therefore, non-parametric Mann-Whitney $U$ tests were used for inferential analyses. A Shapiro-Wilk test was conducted for each of the scales to test hypothesised distribution normality. Results are shown in Table 2. For each scale, scores significantly $(p<.05)$ deviated from a normal distribution. Accordingly, non-parametric analyses were used to evaluate differences between groups. 
Jennifer Sharkey and Barbara Caska

Table 2: Results of Shapiro-Wilk Tests of Distribution Normality

\begin{tabular}{llll}
\hline Scale & W & $\mathrm{n}$ & $\mathrm{p}$ \\
\hline PSS & .98 & 125 & .035 \\
SWLS & .94 & 125 & .000 \\
BIAJS & .98 & 125 & .000 \\
\hline
\end{tabular}

\section{Inferential Analyses}

The first hypothesis was tested by comparing affective job satisfaction across WLB (n $=90)$ and WLM $(n=42)$ groups. A Mann-Whitney $U$ test revealed that the WLB condition ( $\mathrm{Mdn}=15)$ and the WLM condition (Mdn $=16)$ significantly differed in affective job satisfaction levels $(U=1.97, p=.049, r=.17)$. This provided support for Hypothesis 1.

The second hypothesis compared WLB and WLM participants on a) satisfaction with life (SWL), and b) perceived stress (PS). Significant differences in SWL were indicated through a Mann-Whitney test $(U=2.17, p=.030)$, comparing the WLB ( $n=89$, Mdn $=28)$ and the WLM groups $(n=43, M d n=28)$. However, no significant difference $(U$ $=-.40, p=.690$ ) was found between the two groups in PS (WLB $n=86, \mathrm{Mdn}=6$; WLM $\mathrm{n}=41, \mathrm{Mdn}=6)$.

The third hypothesis examined satisfaction with life and affective job satisfaction across the WLM Flexi and WLM Non-flexi groups. A Mann-Whitney test indicated significant differences in SWL between the two groups $(U=-3.05, p=.002, r=.47$; WLM Flexi $n=31$, Mdn = 30; WLM Non-flexi $n=12$; Mdn = 21.5). However, no significant difference in affective job satisfaction was found between WLM Flex $(\mathrm{n}=$ $30 ; \mathrm{Mdn}=16)$ and WLM Non-flex participants $(\mathrm{n}=12 ; \mathrm{Mdn}=15.5 ; \mathrm{U}=-.38, \mathrm{p}=.736)$.

\section{Qualitative Analysis}

\section{Familiarisation with data and initial coding}

The raw data was reviewed to establish familiarity before generating initial codes using Braun and Clarke's thematic analysis (2006). Initial codes were then expanded into themes identifying similar trends amongst responses, e.g., complaints about long working hours, negative impacts on health, positives aspects of working in structured environments, and relations between work and desired standard of living. The themes were continually refined and grouped together, yielding the thematic models shown below. 


\section{Themes}

\section{Question No. 1: "How does your job impact or affect your personal life?"}

Four overarching themes were identified in response to the question of how one's job impacts or affects their personal life. These included potential drawbacks, such as "Takes up too much time"; "Negatively affects mental health." Positive effects were also found, as indicated through themes of "Brings benefits and positivity"; and "Brings structure and balance". Figure 3 illustrates links between emergent themes and subthemes.

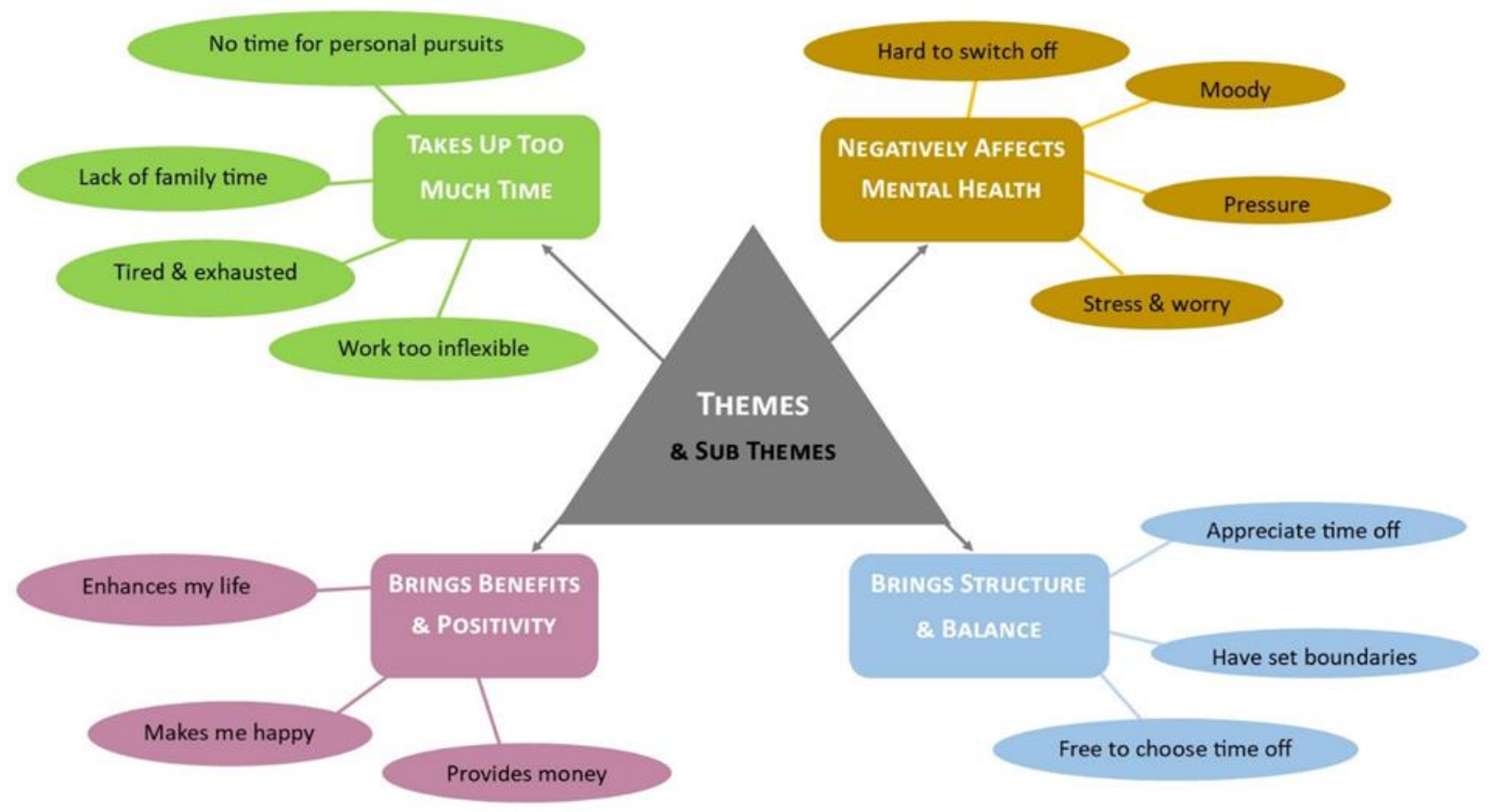

Figure 3: Thematic map: How does your job impact or affect your personal life?

\section{Theme 1: Brings benefits and positivity}

Participants spoke of the many benefits and positive affect their jobs had on them. Some viewed their job as an enhancement to their personal life. For example:

Participant 99: "If work is going well it helps my personal life too."

Participant 22: "I am happy with my job therefore happy with my life."

Others spoke of how remuneration from their job enabled them to fund their personal life and enhance their standard of living:

Participant 118: "It provides me unique opportunities and a gold standard of living."

Participant 21: "Gives me satisfaction and money to fund my personal life." 


\section{Theme 2: Takes up too much time}

A strong theme throughout the answers given was around the issue of time and the negative impact of its restriction on their personal life. Participants also spoke about lack of flexibility with work hours resulting in less time for family or personal pursuits:

Participant 25: "It takes a lot of my personal time and as such it prevents me from fully enjoying my family."

Participant 10: "Restricted with flexibility - main problem. I have to work 9-5:30 no exceptions."

Others acknowledged the role technology played in blurring the boundaries between work and personal time:

Participant 89: "It somewhat impacts due to new technologies breaking down the divide between work time/personal time."

Some took a more pragmatic viewpoint when acknowledging the impact of technology, and its resultant merge between personal life and work:

Participant 83: "Extensively.... but I accept the nature of the role I'm in is labour intensive (in stints). By accepting that and being aware, it makes other of my life easier to assess and manage. Of course, at times, it's straining on my personal life and I've probably lost out on some interests but I'm playing the long game and you must sacrifice to get places. If you think emails are on my phone, research is on my phone, etc... there isn't much getting away from it so I see it that my life and profession are to be managed as one entity as opposed to "my Life and my Job"."

Tiredness as a result of working long hours was also an issue for many participants, resulting in having limited time with family and friends. It also brought on feelings of guilt for some:

Participant 111: "My job is so tiring mentally that I do not want to have many interactions once I am off work. It also impacts the people with whom I spend personal time."

Participant 12: "It's hard to juggle family life and work with young children. Feelings of guilt and being tired."

\section{Theme 3: Brings structure and balance}

Some participants spoke of being able to establish boundaries between their working and personal lives, and having good work-life balance. This seemed to be easier for those who had greater flexibility in their work:

Participant 94: "It is great because I can choose my own days off to a degree as I am my own boss." 
Participant 69: "Not really as I am free to choose my time off."

Participant 7: "My job doesn't affect my personal life adversely. I have a fairly good work life balance."

Other participants regarded the impact their work had on their personal life as something they could control in order to minimise negative effects:

Participant 45: "Tend not to bring work physically nor mentally home with me. This is something I learned to rather than instructed to do."

Participant 4: "I have established boundaries around work and home to make sure they don't impact each other"

\section{Theme 4: Negatively impacts mental health}

There was a strong theme around mental health and the negative impact of work on it. Strong feelings were expressed, with many describing how hard it was to mentally switch off from the stress of their job. Worrying about work when at home was a common complaint amongst some participants:

Participant 18: "Can be worried about managing well in work. Worry at home then."

Participant 19: "Hard to switch off. Lot of support expectations."

Participant 127: "It can be hard to let go, I am often left with the emotions, stress, worry, anxiety, fear, self-doubt, feeling not good enough, inadequate. These feelings can be hard to shake off and so are sometimes clouding who I am in my personal life."

Not being happy in work had the potential to negatively impact participant mood and feelings of happiness:

Participant 35: "It often causes me unhappiness."

Participant 87: "Feel sometimes unsatisfied and therefore more moody in my personal life."

\section{Question No. 2: "What would you change about your job to enhance your personal life?"}

Five overarching themes merged in response to the question of what could be changed about one's job to enhance one's personal life. These spanned increasing pay and changing jobs, improving work structures, and freeing up personal time. An additional theme indicated that some would not change anything about their present job. Themes, along with their sub-themes, are presented in Figure 4. 


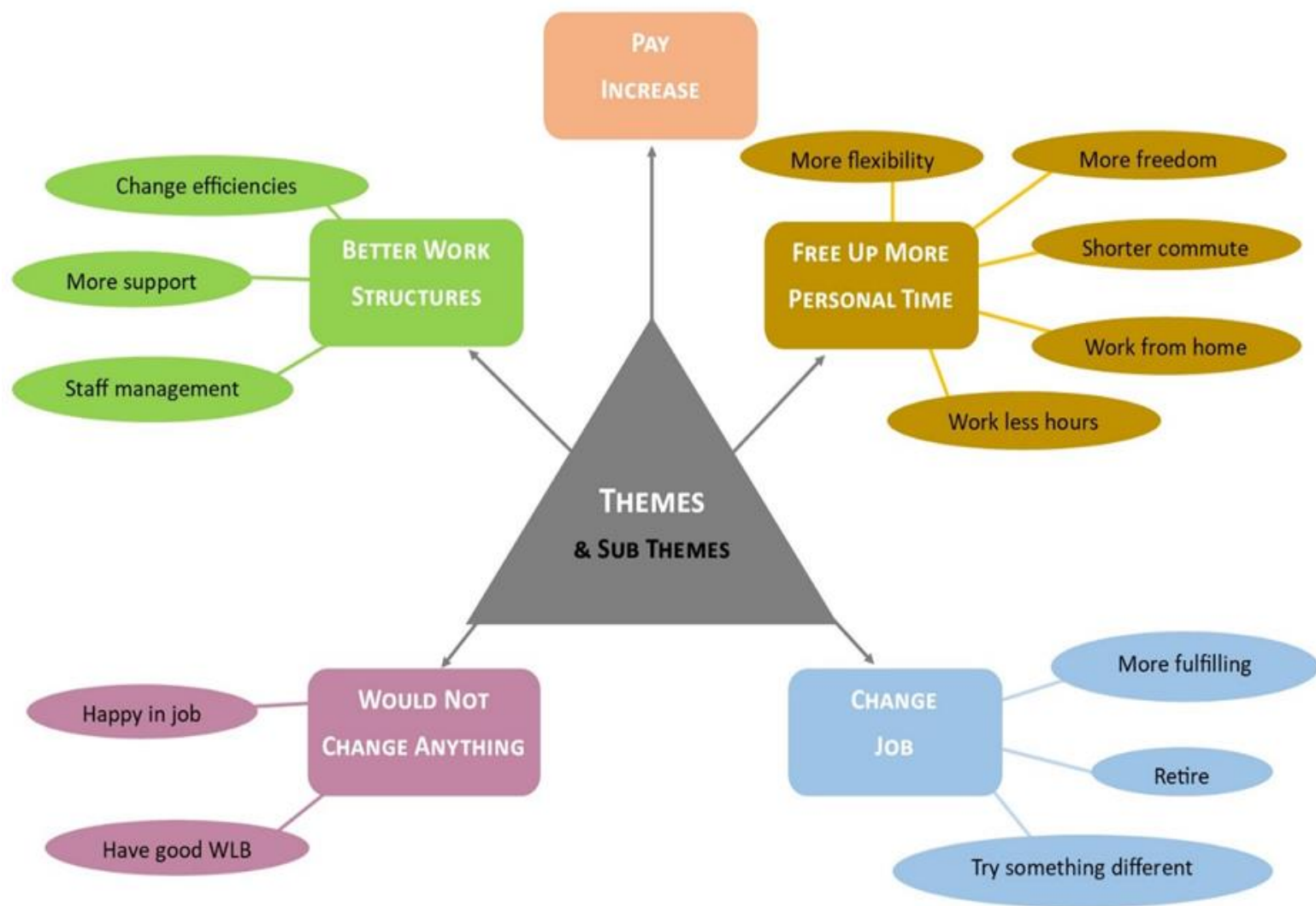

Figure 4: Thematic map: what would you change about your job to enhance your personal life?

\section{Theme 1: Pay increase}

For some participants, the only change they would make to their jobs in order to enhance their personal lives would be an increase in earnings:

Participant 30: "Better salary!"

\section{Theme 2: Better work structures}

Some participants expressed frustration about in-place work structures, and felt that improvements were needed to foster engagement and better use of skillsets.

Participant 111: "I would have a job that allowed me to utilise my skills, not one that dealt with so many topics which I find exhausting and uninteresting."

Participant 93: "Make it more challenging."

Participant 127: "More support, training, time to do paperwork, team building, skills developing." 


\section{Theme 3: Free up more personal time}

Many participants indicated a strong desire to change their working hours, to avoid interference with personal time:

Participant 43: "I would like to be able to plan my work commitments/ tasks so they better align with my personal life's commitments. This is not very realistic though."

Participant 64: "Minimising the amount of work I need to take home."

Some participants spoke of taking control over any encroachment on non-work hours:

Participant 83: "I think it's important if you have access to "work" outside of work, on your phone or otherwise, that you decide when you are offline. This is probably the one thing I've changed, and had to change..."

A greater level of flexibility and freedom in the workplace was also a common thread found throughout the answers:

Participant 10: "Having more flexibility in my working hours."

Participant 48: "Would like to be able to work slightly less hours. Getting home earlier in the evening would make a huge difference."

Many participants expressed a wish to have the option of working from home and a reduced commute. Others wanted to work shorter days or change over to part-time work. Some believed this could be achieved with better use of technology and/or hiring more staff:

Participant 46: "Either a combination of working from home and the workplace or hire additional staff to reduce the long days of work."

Participant 103: "Less travel from Donegal to Dublin for meetings/greater use of technology."

\section{Theme 4: Would not change anything}

Some participants had no desire to change anything about their jobs and were happy with the status quo. Those who elaborated further on their reasons for being happy with their current work set-up spoke of an element of freedom and autonomy existing in their lives:

Participant 125: "Not much, I'm very lucky in the sense that my job has a great work/life balance and allows for exploration of interests."

Participant 62: "I have created my job and I really like it."

Participant 69: "It does not impact my personal life as I can do my work as I see fit most of the time." 


\section{Theme 5: Change job}

Some wished to change their roles entirely, retire, or try something different to gain greater fulfilment, even with less pay:

Participant 82: "My current role is not what I would like to do long term. I am well paid so appreciate that I need to work hard and am happy to do so but I would prefer to do this in a role that I truly enjoy even if that involves lower pay."

\section{Question No. 3: "What motivates you about working?"}

Figure 5 presents emergent themes and subthemes in response to the question on work motivators. Over-reaching themes encompassed internally experienced "Learning and improving" and "Job satisfaction". Additional themes included the opportunity for "People interaction" and "The pay cheque".

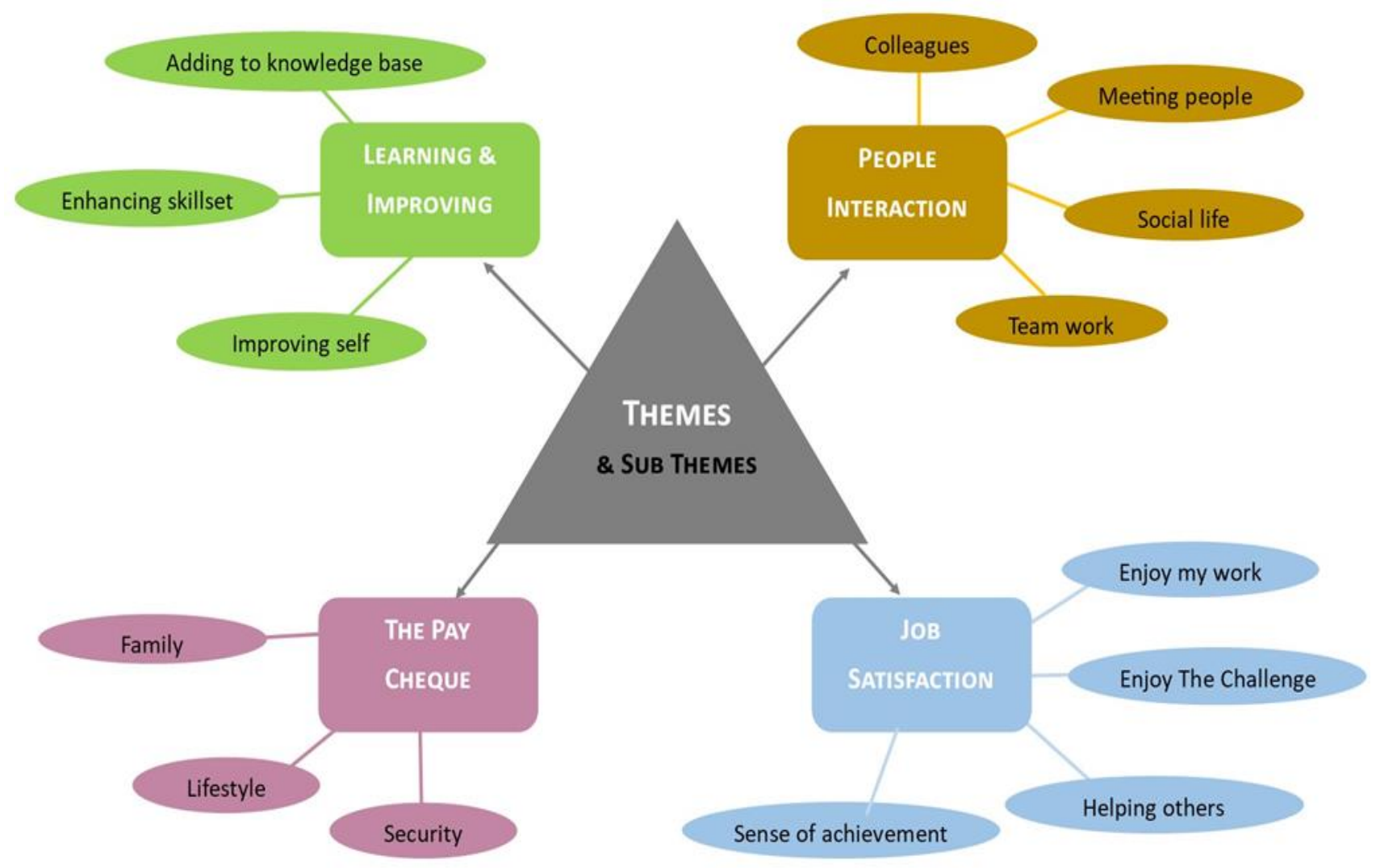

Figure 5: Thematic map: what motivates you about working?

\section{Theme 1: Learning and improving}

Learning new things and improving their skillset acted as motivating forces for some participants, for example:

Participant 90: "The challenge to continuously improve myself and learn new things." 
Participant 128: "Learning new things and bettering skills I have."

Others found that the challenge of each day being different served as a motivator:

Participant 118: "Every day can be different, but all with the same background of technology consulting. Different clients and different technologies, but all technologies."

Some wanted to make a difference in the lives of others, while at the same time bettering themselves:

Participant 110: "The idea of making a difference in someone's life and wanting to constantly become better at what I do."

\section{Theme 2: People interaction}

A strong motivating force for many was the positive experience gained through interacting with others, whether clients, customers or fellow colleagues. Participants were quite enthusiastic about this aspect of their working lives:

Participant 12: "I love what I do, teaching something I am very passionate about and interacting with people."

Participant 90: "The possibility of changing a person's life."

Participant 41: "Making a difference to as many people as possible."

Those who developed good relations with colleagues and enjoyed teamwork were further motivated by these experiences:

Participant 82: "Being in a collaborative environment where a small a team we try to achieve goals is a real motivator for me."

Participant 120: "Great colleagues, interesting work."

The social life and simply experiencing the positives of being with others was another force identified:

Participant 51: "Being useful, having a purpose, socialising."

Participant 17: "I love to interact with people."

\section{Theme 3: Satisfaction}

Deriving satisfaction was a very strong theme among respondents both from a professional and personal point of view, with a link between job satisfaction and personal satisfaction:

Participant 68: "Job satisfaction. I can see that what I do has a positive impact on the children I work with."

Participant 88: "Personal fulfilment." 
Participant 52: "Personal satisfaction and money."

Satisfaction also stemmed from helping others, with a knock-on effect of making some participants feel good about themselves:

Participant 22: "The fact that I make people feel good."

Participant 45: "I work in training and education so seeing others achieve makes me feel good about myself."

Some participants were motivated by the feelings they got from accomplishing tasks and from feeling useful. Others were encouraged when their efforts were acknowledged by their employer. Some enjoyed the challenge of a job well done as well as helping the business to be successful:

Participant 13: "Feeling of accomplishment and being useful."

Participant 131: "Acknowledgement from my employer of my work."

Participant 109: "Doing things right and to the betterment of the business."

\section{Theme 4: The pay cheque}

Some participants cited money as their sole reason to work, as it was necessary to meet basic requirements:

Participant 49: "Got to pay the rent and bills."

Participant 35: "Security."

Others indicated that while money was the main driving force for work, personal interest in their job was also important:

Participant 43: "Interest in the work itself is a factor but mostly it is down to pay."

Participant 96: "Money. And career progression and achieving/exceeding targets. But mainly money."

But for some, it was all about the pay cheque:

Participant 37: "Pay day. I have zero self-worth invested in my job. I'm not a career person."

Others were keen to believe that money could not be the only driving force behind going to work. Some linked achieving their goals with basic survival, which brought with it a sense of reward:

Participant 83: "I think we all work for money but there has to be more to it to be satisfied. My role is very goal-orientated because if we don't achieve our goals we're out of a job. The whole process gets me up and motivated as a result... it's rewarding work I guess." 


\section{Discussion}

The purpose of this mixed-methods research study was to test the traditional work-life balance concept that workers experience better well-being by being able to psychologically switch on and off. By bringing in both elements of quantitative and qualitative analyses, it was hoped the findings would offer a deeper understanding surrounding workplace well-being, as well as garnering valuable insights pertaining to workers' thoughts and needs in this Information Age.

As hypothesised, results indicated significantly higher levels of both life satisfaction and job satisfaction among WLM participants compared to WLB members. Previous research suggests that satisfied employees can result in better performance output (Zelenski, Murphy and Jenkins, 2008) and increased revenue (Oswald, Proto and Sgroi, 2015). Enhanced employee productivity was also found to be linked to greater levels of loyalty and customer care (Sgroi, 2015), as well as the formation of strong and thriving communities (Jeffrey et al., 2014).

In this study, the WLM group was split into two groups-those with and without flexible arrangements in their jobs - and, as hypothesised, the more flexible group reported significantly higher life satisfaction levels. This suggests there is real merit as demonstrated in previous research (Kelly et al., 2014) in management intervening and constructing the correct level of support and flexibility for workers.

Qualitatively, participants were asked to describe how their jobs impacted their personal lives, what they would like to see changed, and what motivated them to work. Themes that were identified ranged from positive impacts such as structure and financial security, to negative mental aspects such as worry, stress and unhappiness that spilled over into workers' personal lives. Such findings highlight the value of Kelloway and Day's holistic model that addresses many of these concerns (2005b).

A strong complaint amongst participants was they did not have enough time to spend with family or on personal pursuits. Desired changes ranged from better work structures to more flexible working arrangements. Some suggested that these alterations should be possible with today's remote technology. A growing interest amongst Irish employees in working from home (Gordon, 2018) highlights a need for progress in this area. Some participants were quite happy with the ratio of work-life balance they had already achieved in their lives.

Motivating factors ranged from the pay cheque to a real desire to want to learn more and improve skills. Many participants expressed how work challenges, plus interacting with clients, customers and colleagues, were key motivators for them. Many also had a strong desire to help others.

Whilst a few participants in this study spoke of achieving a good work-life balance, the majority indicated struggles with long working hours and commutes leaving them too exhausted to enjoy personal pursuits. This is consistent with Day, Kelloway and Hurrell's (2014) consideration of balance as a misleading representation of what today's workers achieve across their work and personal lives. 
The findings of the present study reinforce the importance of separating work and nonwork hours. Job and life satisfaction levels were higher for workers who were not tied to the workplace every day. This suggests that a degree of flexibility may be key in achieving greater well-being. Wood (2016) similarly found that restricted flexibility had a negative impact on workers.

Participants expressed a need for more support and better work structures in the workplace. They indicated how much they were motivated by new challenges, learning, and helping others. Interestingly, this suggests that despite extensive research on work-life over the past three decades, there remains a need to create opportunities which allow for employee development and growth. The importance of addressing higher order needs in the workplace was posited in the early motivational theories of Herzberg (1987), and Hackman and Oldham (1975). It appears that related work-based opportunities remain an important consideration to employees today.

Based on findings from this study, a need for organisations to address basic, lower order needs also continues to influence workers. A strong theme of exhaustion from participants working and commuting over long periods emerged, as well as complaints of pressure to perform whilst 'off the job'. Some participants spoke of how today's technology blurs the lines between their work and private lives. This was either accepted as a new way of living, or found too intrusive and invasive.

The strengths of this study lie mainly in its attempt to learn and understand more about the well-being of today's Information Age workers by giving them an opportunity to put their thoughts and needs into their own words. None of the qualitative questions presented were compulsory, yet many chose to take the time to talk about themselves-some quite personally. The quantitative element of this study used wellestablished scales. Findings were enhanced by the richness of qualitative data gathered and analysed. The sample size was quite adequate, with a good split between numbers in the WLM and WLB groups. Participants provided a good representation across age and sex.

\section{Conclusion}

The findings in this study call for a need for a more contemporary approach by researchers when analysing and addressing variables that help to promote psychologically healthy workplaces, and for these new learnings to be communicated effectively to employers and policymakers. Psychological well-being in the workplace is an area that has been heavily researched by organisational psychologists, but perhaps what is lacking are real practical models that are fit for purpose in creating healthy work environments and healthy minds. Employers may not fully understand and recognise the far-reaching and mutual benefits to be had by adopting and managing flexible work constructs. Failure to be cognisant of peoples' needs comes with serious consequences, as has been evidenced across the globe in recent years. Herzberg (1987) spoke of how people want to be interested, motivated and engaged, but not forgotten, ignored or left behind. Significant findings, such as those found in this study and comparable studies, coupled with Kelloway and Day's (2005b) holistic model of adopting a broad approach, should act as a blueprint for future researchers, 
policymakers and management interested in harvesting psychological well-being in today's workplaces.

\section{REFERENCES}

Ainge Roy, E. (2018) 'Work four days, get paid for five: New Zealand company's new shorter week', The Guardian International Edition, 9 February 2018 [Online]. Available at: https://www.theguardian.com/world/2018/feb/09/work-four-days-get-paid-for-five-newzealand-companys-new-shorter-week (Accessed 17 Dec. 2018).

Attaran, M., Attaran, S. and Kirkland, D. (2019) 'The need for digital workplace: increasing workforce productivity in the Information Age', International Journal of Enterprise Information Systems, 15(1), pp.1-23. doi: 10.4018/IJEIS.2019010101.

Braun, V. and Clarke, V. (2006) 'Using thematic analysis in psychology', Qualitative Research in Psychology, 3(2), pp.77-101. doi: 10.1191/1478088706qp063oa.

Chang, A., McDonald, P. and Burton, P. (2010) 'Methodological choices in work-life balance research 1987 to 2006: a critical review', The International Journal of Human Resource Management, 21(13), pp. 2381-2413. doi: 10.1080/09585192.2010.516592.

Chen, A. and Karahanna, E. (2018) 'Life interrupted: the effects of technology-mediated work interruptions on work and nonwork outcomes', MIS Quarterly, 42(4), pp.1023-1042.

Chmiel, N., Fraccaroli, F. and Sverke, M. (eds.) (2017) An introduction to work and organizational psychology. 3rd ed. NJ: Wiley Blackwell.

Cohen, S., Kamarck, T. and Mermelstein, R. (1983) 'A global measure of perceived stress', Journal of Health and Social Behavior, 24(4), pp. 385-396. https://doi.org/10.2307/2136404

Cooper, C. and Cartwright, S. (1994) 'Healthy mind; healthy organization - a proactive approach to occupational stress', Human Relations, 47(4), pp. 455-471.

https://doi.org/10.1177/001872679404700405

Day, A., Kelloway, E. and Hurrell, J. (eds.) (2014) Workplace well-being: how to build psychologically healthy workplaces. Hoboken, NJ: Wiley-Blackwell.

Department of Employment Affairs and Social Protection (2019) 'Employment (Miscellaneous Provisions) Act 2018'. Available at:

http://www.welfare.ie/en/pages/Employment (Miscellaneous Provisions) Act 2018.aspx

(Accessed 14 Mar. 2019).

Diener, E., Emmons, R., Larsen, R. and Griffin, S. (1985) 'The satisfaction with life scale', Journal of Personality Assessment, 49(1), pp.71-75.

https://doi.org/10.1207/s15327752jpa4901 13

Gambles, R., Lewis, S. and Rapoport, R. (2006) The myth of work-life balance. Chichester, England: John Wiley and Sons.

Gordon, D. (2018) 'Home work: why more Irish employees want to work remotely', Irish Times, 14 December 2018 [Online]. Available at: 
https://www.irishtimes.com/business/work/home-work-why-more-irish-employees-want-towork-remotely-1.3727545. (Accessed: 14 March 2019).

Gyanchandani, R. (2017) 'A qualitative study on work-life balance of software professionals', IUP Journal of Organizational Behavior, 16(4), pp. 53-67.

Hackman, J. and Oldham, G. (1975) 'Development of the Job Diagnostic Survey', Journal of Applied Psychology, 60(2), pp. 159-170. Available at:

http://www.jwalkonline.org/upload/pdf/Hackman\%20\%26\%20Oldham\%20(1975)\%20-

\%20Development\%20of\%20the\%20JDS.pdf. (Accessed: 17 February 2019).

Health and Safety Authority (2018) 'Bullying at work'. Available at:

https://www.hsa.ie/eng/Workplace Health/Bullying at Work/ (Accessed: 17 February 2019].

Herzberg, F. (1987) 'One more time: how do you motivate employees?' Harvard Business

Review, 65(5), pp. 109-120. Business Source Complete, EBSCOhost [Online]. (Accessed:

18 December 2018).

Hinsliff, G. (2013) 'The merge: how our work-life balance is changing', The Guardian, 1 January 2013 [Online] Available at: https://www.theguardian.com/money/2013/jan/01/mergework-life-balance (Accessed: 8 April 2018).

Hughes, J. and Bozionelos, N. (2007) 'Work-life balance as source of job dissatisfaction and withdrawal attitudes: an exploratory study on the views of male workers', Personnel Review, 36(1), pp. 145-154. https://doi.org/10.1108/00483480710716768

Hyacinth, B. (2017) 'Why employees come first, customers second, and shareholders third', Linkedln, 15 November 2017 [Online]. Available at: https://www.linkedin.com/pulse/whyemployees-come-first-customers-second-third-brigette-hyacinth?trk=eml-

email feed ecosystem digest 01-recommended articles-7-

UnknownandmidToken=AQFJMkyVj6ShZwandfromEmail=fromEmailandut=2CwK6z2eosZ8 01 (Accessed: 17 December 2018).

Jeffrey, K., Mahony, S., Michaelson, J. and Abdalla, S. (2014) 'Well-being at work: a review of the literature', London, UK: New Economics Foundation. Available at:

https://neweconomics.org/uploads/files/71c1bb59a2ce151df7 8am6bqr2q.pdf (Accessed: 8 April 2018).

Judge, T., Thoresen, C., Bono, J. and Patton, G. (2001) 'The job satisfaction-job performance relationship: a qualitative and quantitative review', Psychological Bulletin, 127(3), pp. 376-407. https://doi.org/10.1037/0033-2909.127.3.376.

Kelloway, E. and Day, A. (2005a) 'Building healthy workplaces: where we need to be', Canadian Journal of Behavioural Science/revue canadienne des sciences du comportement, 37(4), pp. 309-312. PsycARTICLES, EBSCOhost [Online]. (Accessed: 17 December 2018).

Kelloway, E. and Day, A. (2005b) 'Building healthy workplaces: what we know so far', Canadian Journal of Behavioural Science/revue canadienne des sciences du comportement, 37(4), pp. 223-235. PsycARTICLES, EBSCOhost [Online]. (Accessed: 17 December 2018).

Kelly, E., Moen, P., Oakes, J., Fan, W., Okechukwu, C., Davis, K., Hammer, L.B., Kossek, E.E., Berkowitz King, R., Hanson, G.C., Mierzwa, F. and Casper, L.M. (2014) 'Changing 
work and work-family conflict: evidence from the work, family, and health network', American Sociological Review, 79(3), pp. 485-516. doi: 10.1177/0003122414531435.

Kossek, E.E. and Ozeki, C. (1999) 'Bridging the work-family policy and productivity gap: A literature review', Community, Work and Family, 2(1), pp. 7-32. Business Source Complete, EBSCOhost [Online]. (Accessed: 17 December 2018).

Messersmith, J. (2007) 'Managing work-life conflict among information technology workers', Human Resource Management, 46(3), pp.429-451. Business Source Complete, EBSCOhost [Online]. (Accessed: 8 April 2018).

Moorman, R. (1993) 'The influence of cognitive and affective based job satisfaction measures on the relationship between satisfaction and organizational citizenship behavior', Human Relations, 46(6), pp. 759-776. https://doi.org/10.1177/001872679304600604.

Motro, D., Ordonez, L. and Pittarello, A. (2014) 'Investigating the effects of anger and guilt on unethical behavior: a self regulation approach', Academy of Management Proceedings, 2014(1), pp. 1571-1576. Business Source Complete, EBSCOhost [Online]. (Accessed: 8 December 2018).

Murthy, M. and Shastri, S. (2015) 'A qualitative study on work life balance of employees working in private sector', International Journal of Recent Scientific Research, 6(7), pp.51605167. Available at: http://www.recentscientific.com/sites/default/files/2926.pdf. (Accessed: 8 December 2018).

Oswald, A., Proto, E. and Sgroi, D. (2015) 'Happiness and productivity', Journal of Labor Economics, 33(4), pp.789-822. doi: 10.1086/681096.

Pavot, W., Diener, E., Colvin, C. and Sandvik, E. (1991) 'Further validation of the satisfaction with life scale: evidence for the cross-method convergence of well-being measures', Journal of Personality Assessment, 57(1), pp.149-161. Business Source Complete, EBSCOhost [Online]. (Accessed: 8 December 2018).

Piliavin, J. and Siegl, E. (2007) 'Health benefits of volunteering in the Wisconsin Longitudinal Study', Journal of Health and Social Behavior, 48(4), pp.450-464. doi: 10.1177/002214650704800408.

Russell, H., Maitre, B., Watson, D. and Fahey, É. (2018) 'Job stress and working conditions: Ireland in comparative perspective', ESRI Research Series. Available at: https://www.esri.ie/pubs/RS84.pdf (Accessed 18 Dec. 2018).

Schieman, S., Glavin, P. and Milkie, M. (2009) 'When work interferes with life: work-nonwork interference and the influence of work-related demands and resources', American Sociological Review, 74(6), pp. 966-988. https://doi.org/10.1177/000312240907400606.

Sgroi, D. (2015) 'Happiness and productivity: understanding the happy productive worker', SMF-CAGE Global Perspectives Series Paper 4, pp.2-20. Available at: http://www.smf.co.uk/wp-content/uploads/2015/10/Social-Market-Foundation-PublicationBriefing-CAGE-4-Are-happy-workers-more-productive-281015.pdf. (Accessed: 18 December 2018). 
Smith, J. (2016) 'Here's why workplace stress is costing employers $\$ 300$ billion a year', Business Insider, 6 June 2016 [Online]. Available at: https://www.businessinsider.com/howstress-at-work-is-costing-employers-300-billion-a-year-2016-6 (Accessed 4 Mar. 2019).

Thompson, E. and Phua, F. (2012) 'A brief index of affective job satisfaction', Group and Organization Management, 37(3), pp. 275-307. https://doi.org/10.1177/1059601111434201.

Vallejo, M., Vallejo-Slocker, L., Fernández-Abascal, E. and Mañanes, G. (2018) ‘Determining factors for stress perception assessed with the perceived stress scale (PSS-4) in Spanish and Other European Samples', Frontiers in Psychology, 9.

https://doi.org/10.3389/fpsyg.2018.00037.

Warhurst, C., Eikhof, D. and Haunschild, A. (eds.) (2008) Work less, live more?: a critical analysis of the work-life boundary. Houndmills: Palgrave Macmillan.

Warren, T. (2015) 'Work-life balance/imbalance: the dominance of the middle class and the neglect of the working class', The British Journal of Sociology, 66(4), pp. 691-717. doi: 10.1111/1468-4446.12160.

Wood, A. (2016) 'Flexible scheduling, degradation of job quality and barriers to collective voice', Human Relations, 69(10), pp.1989-2010. https://doi.org/10.1177/0018726716631396.

Wood, S. J., and Michaelides, G. (2016) 'Challenge and hindrance stressors and wellbeingbased work-nonwork interference: a diary study of portfolio workers', Human Relations, 69(1), 111-138. https://doi.org/10.1177/0018726715580866.

Zelenski, J., Murphy, S. and Jenkins, D. (2008) 'The happy-productive worker thesis revisited', Journal of Happiness Studies, 9(4), pp. 521-537. https://doi.org/10.1007/s10902008-9087-4. 